\title{
The effect of educational intervention on healthcare providers' knowledge, attitude, \& practice towards antimicrobial stewardship program at, National Liver Institute, Egypt
}

Marwa Ali Tahoon', Magdy Mohammed Khalil², Essam Hammad³ ${ }^{3}$ Wesam Saber Morad', Samah Mohammed awad ${ }^{4}$ and Sameera Ezzat ${ }^{1 *}$

\begin{abstract}
Background: Inappropriate use of antimicrobials results in rapid emergence of resistance, selection pressure on resistant microorganisms, adverse reactions, and treatment failures. An effective approach to improving antimicrobial use in healthcare settings is a structured antimicrobial management program known as antimicrobial stewardship (AMS). Education and training is considered a backbone element of AMS program. This study aimed to evaluate the impact of educational program on the knowledge, attitude, and practice (KAP) of healthcare providers (HCPs) towards antimicrobial stewardship before and after the educational program at the surgery department and surgical ICU, National Liver Institute hospital (NLI), Egypt.

Results: Among the 69 invited HCPs, 48 attended the educational program sessions with attendance response rate about $70 \%$. Regarding pre-educational KAP score of the respondents' physicians and pharmacists, 39.3\% of them had good knowledge score, $85.7 \%$ of them had positive attitude, \&and 31.8\% of physicians had good practice score; however, $100 \%$ of the pharmacists had poor practice. Regarding the respondents' nurse, the pre-education mean score of knowledge was 13.3/20, attitude 14.8/16, and practice 9.3/14. Following educational program, there was a significant improvement in knowledge, attitude, and practice of the respondents' health care providers $(P<0.001)$; on the contrary, there was no significant improvement in the practice of pharmacists $(P>0.05)$.

Conclusion: The implemented educational program was successful in improving the knowledge, attitude, and practice of HCPs; therefore, continuous efforts are needed to implement more educational programs to increase awareness towards AMS among HCPS,
\end{abstract}

Keywords: Antimicrobial stewardship, Resistance, Knowledge, Attitude, Practice

\footnotetext{
* Correspondence: drsekhir@yahoo.com

${ }^{1}$ Epidemiology and Preventive Medicine Department, National Liver Institute, Menoufia University, Gamal Abdel Nasser Street, Shebein El-Kom, Menoufia,

Egypt

Full list of author information is available at the end of the article
} 


\section{Background}

Combating the increasing prevalence of antimicrobial resistance bacteria has become one of the greatest public health threats globally [1]. Infections with antimicrobialresistant organisms resulted in increased morbidity, mortality, longer hospital stays, and dramatically increased healthcare costs [2, 3]. The US Centers for Disease Control and Prevention (CDC) is undertaking a nationwide effort to appropriately improve antimicrobials use in healthcare settings [4]. As a result, the CDC and others recommend the implementation of antimicrobial stewardship (AMS) programs [5]. AMS programs are a set of multidisciplinary interventions that aim to ensure the rational use of antimicrobials by preventing their unnecessary use and to provide targeted and limited therapy in conditions where they are necessary [6]. AMS helps clinicians to improve the quality of patient care and improve patient safety. Moreover, these programs often achieve these benefits while saving hospital money [7]. A major cause of misuse is lacking knowledge of prescribing of antimicrobials in many categories of health care workers [8]. Therefore, education, as a backbone feature of this program and one of CDC core element of AMS, is considered essential to teaching the knowledge necessary for effective stewardship and can influence physicians' prescribing behavior $[9,10]$. Several educational interventions have been shown to improve antimicrobial prescribing practices and infection control [11-13]. Up to the researchers' knowledge, no interventional study was conducted in Egypt to improve healthcare providers' knowledge, attitude, and practices towards AMS. Therefore, the aim of this study is to evaluate the impact of educational programs on the knowledge, attitude, and practice of healthcare providers towards antimicrobial stewardship (AMS) in the surgery department and surgical ICU, National Liver Institute (NLI), Egypt. Owing to the lack of similar studies in the area, the results from this study can be utilized in benefiting patients by identifying problems associated with inappropriate use of antibiotics.

\section{Methods}

\section{Ethical point of research}

- Firstly, the study protocol submitted to get approval from the Research Ethics Review committee at the National Liver Institute (NLI) (IRB00003413), Menoufia University.

- Written consent was taken from subjects who participated in the study for answering the questionnaire after being informed of the full details of the research including risks and benefits.

- Confidentiality of the information assured.

\section{Settings and study subjects}

A pre-post interventional study was conducted at the surgical department and ICU, NLI, located in Menoufia governorate, Egypt, with a bed capacity of 40. The aim of the program is to educate healthcare providers about AMS, which was conducted from April 2018 to June 2018. Healthcare providers include medical doctors, nurses, and pharmacists working throughout this department. All healthcare providers, who were willing to participate, were included in the study.

\section{The study questionnaires establishment}

For the respondents' physicians and pharmacists, the self-administered questionnaire was adapted from previous studies with similar objectives [14, 15]. Another questionnaire designed in the Arabic language and referenced from previous studies with similar objectives was designed for nurses $[5,16]$.

\section{Data collection tool and procedure}

A questionnaire with four parts containing questions about demographic characteristics of healthcare providers, questions about knowledge (knowledge about AMR, familiarity with terms (antimicrobial stewardship, antibiogram, and antibiotic resistance), and knowledge on the role of AMS), attitude (overall attitude about antimicrobial resistance and AMS), and practices (related to prescribing) was distributed among healthcare providers who fulfill the inclusion criteria and are willing to participate in the study.

Prior to the beginning of the first workshop session, the health care providers were requested to fulfill the study questionnaires and were allowed $10 \mathrm{~min}$ to complete it and give it back to the educator. The questionnaire was fulfilled by interviewees. This represents the preintervention baseline data. After 6 months of educational intervention, post-intervention questionnaires were administrated to health care providers and allowed also 10 min to be completed and return the form.

\section{Educational intervention}

It was carried out via preparing lectures regarding antimicrobial stewardship principles and guidelines. The lectures were adapted and simplified from the WHO antimicrobial stewardship online course modules [17]. These lectures were prepared and presented by the members of AMS team at NLI. There were separate sessions for physicians, pharmacists, and nurses. We presented lectures in English for both physicians and pharmacists and in Arabic language for nurses.

For surgeon and intensivist, they were given condensed theoretical sessions regarding basic concept of antibiotics and antimicrobial stewardship, the principles of antimicrobial prescribing, antimicrobial resistance, and most frequent infection guideline (urinary tract 
infections, community-acquired respiratory tract infections, skin and soft tissue infections, antimicrobial surgical prophylaxis, intra-abdominal infections, and others).

For pharmacists, they were given theoretical sessions regarding the basic concept, the principles of antimicrobial prescribing, and the role of the pharmacist in the stewardship.

For nurses, they were given theoretical sessions regarding antimicrobial resistance, AMS definition, and the importance of AMS, why AMS is required, classification of bacteria, principles of empirical therapy, and the role of nursing in AMS.

\section{Teaching tools}

A blended teaching method was used:

1. Two hours of teaching sessions conducted through PowerPoint presentation, videos, and clinical scenarios. About nine sessions were done (six for physicians, two for nurses, and one for pharmacists)

2. Granting booklet including antibiotics guidelines for the most infectious diseases based on IDSA practice guidelines for physicians and pharmacists.

3. WhatsApp group for sharing messages, videos, and photos: we created two WhatsApp groups-one for surgical department residents, and the other for surgical ICU residents.

\section{Scoring system and data management}

Regarding knowledge of physicians and pharmacists, their knowledge was evaluated using 11 questions which was divided into three parts: (1) four questions to assess the knowledge regarding the antimicrobial resistance using a 5 -point Likert scale $(5=$ strongly agree, $4=$ agree, 3 = disagree, 2 = strongly disagree, $1=$ no opinion), (2) three questions to assess familiarity with terms (included antimicrobial stewardship term, antibiogram term, and antibiotic resistance term) using a 5-item scale ( 5 = very familiar, $4=$ familiar, I heard the term and have some familiarity, 3 = somehow familiar, 2 = not familiar, I heard the term but I am not sure what it is, $1=$ not at all familiar, I have never heard of it), and (3) four questions to assess their knowledge regarding the role of AMS using a 5 -item scale ( $5=$ effective, $4=$ ineffective, $3=$ very ineffective, $2=$ do not know, $1=$ not applicable). Outcomes regarding knowledge were dichotomized as "good" versus "poor." For this, scores for knowledge $\geq 65 \%$ considered good.

Regarding the attitude of physicians and pharmacists, six questions were designed to assess the attitude of physicians and pharmacists about antimicrobial stewardship program by asking the respondents to rate their level of attitude using five items scale $(5=$ strongly agree, $4=$ agree, 3 = disagree, $2=$ strongly disagree, $1=$ no opinion). Outcomes regarding attitude were dichotomized as "positive" versus "negative." For this, scores for attitude $\geq 75 \%$ were considered positive.

Regarding the practice of physicians and pharmacists, for physicians, 11 questions were addressed to assess their practice and for pharmacists; eight questions were used to assess their pharmacists using a 5 -item scale $(5=$ always, 4 = often, 3 = occasionally, $2=$ rarely, $1=$ never). Outcomes regarding practices were dichotomized as "good" versus "poor." For this, scores for practices $\geq 70 \%$ were considered good.

For nurses, ten questions to assess knowledge using a 3 -item scale $(2=$ agree, $1=$ to what extent, $0=$ disagree $)$ with knowledge score range from 0 to 20 , eight questions for attitude with a scoring system used $(2=$ agree, $1=$ to what extent, $0=$ disagree) ranging from 0 to 16 , and seven questions for practices were used with a 3item scale $(2=$ always, $1=$ sometime, and $0=$ never $)$ ranging from 0 to 14 .

\section{Statistical analysis}

Data was analyzed using Statistical Package for Social Sciences (SPSS) version 20 (SPSS Inc., Chicago, IL, USA). The descriptive analysis was done using mean and standard deviation (SD) for continuous variables and percentage for qualitative variables. Checking for normality was carried out using Kolmogorov-Smirnov test (with $P$ value $<0.05$ indicating a not normally distributed continuous variable). Wilcoxon test was used to evaluate pre-post not normally distributed continuous data. McNemar's test was used to evaluate differences in categorical variables between pre- and post-workshop data. For all statistical analysis, a $P$ value of less than 0.05 was considered statistically significant, and all tests were two tailed.

\section{Results}

From the 69 health care providers that were invited to the educational workshops, only 48 attended the educational workshop with a response rate of $70.0 \%$. Among them, 22 (45.8\%) were physician, 6 (12.5\%) pharmacist, and 20 (41.7\%) nurses. The educational workshops about AMS among the respondents' physicians and pharmacists were effective in increasing percent of good knowledge from $39.3 \%$ preintervention to $100 \%$ post-intervention, and this effect was statistically significant $(P$ value $<0.001)$ (Table 1$)$ and also was effective in improving knowledge of the respondents' nurses with total score $13.3 / 20$ pre-intervention vs. $18.0 / 20$ post-intervention $(P<0.001)$ (Table 2$)$.

For the pre-education basic knowledge of the respondents' physicians and pharmacists about antimicrobial use, the majority of them (53.6\%) agreed and $35.7 \%$ of HCP strongly agreed on if antibiotics are used inappropriately, they can lead to resistance, and on incorrect use 
Table 1 Total knowledge, attitude, and practice score of respondents' physicians and pharmacists regarding antimicrobial stewardship program before and after the educational program

\begin{tabular}{|c|c|c|c|c|c|c|}
\hline & \multicolumn{2}{|c|}{ Pre-education } & \multicolumn{2}{|c|}{ Post-education } & \multirow[t]{2}{*}{ McNemar's test } & \multirow[t]{2}{*}{$P$ value } \\
\hline & $n$ & $\%$ & $n$ & $\%$ & & \\
\hline \multicolumn{7}{|c|}{ Total knowledge score } \\
\hline Good ( $\geq 65 \%)$ & 11 & 39.3 & 28 & 100.0 & 21.6 & $0.001^{*}$ \\
\hline Poor (<65\%) & 17 & 60.7 & 0 & 0.0 & & \\
\hline \multicolumn{7}{|l|}{ Attitude } \\
\hline Positive ( $\geq 75 \%$ ) & 24 & 85.7 & 28 & 100.0 & 4.3 & $0.01^{*}$ \\
\hline Negative $(<75 \%)$ & 4 & 14.3 & 0 & 0.0 & & \\
\hline \multicolumn{7}{|l|}{ Physicians practice } \\
\hline Good ( $\geq 70 \%)$ & 7 & 31.8 & 21 & 95.5 & 19.2 & $0.001^{*}$ \\
\hline Poor (<70\%) & 15 & 68.2 & 1 & 4.5 & & \\
\hline \multicolumn{7}{|l|}{ Pharmacists practice } \\
\hline Good ( $\geq 70 \%)$ & 0 & 0.0 & 2 & 33.3 & 1.2 & 0.25 \\
\hline Poor $(<70 \%)$ & 6 & 100.0 & 4 & 66.7 & & \\
\hline
\end{tabular}

*Significant

of antibiotics can lead to ineffective treatment. They also agreed that incongruous use of antibiotics can lead to increased adverse effects (78.6\%) and almost all agreed that it would be an additional burden of medical cost to the patient (96.4\%) (Fig. 1).

Regarding the pre-education familiarity of the respondents' physicians and pharmacists with terms, the majority of them $(50.0 \%)$ were very familiar with the term antibiotic resistance whereas the majority of HCPs are not familiar with the term antimicrobial stewardship (67.8\%) and antibiogram (82.2\%) (Fig. 2).

Regarding the pre-education knowledge of the respondents' physicians and pharmacists about effectiveness of antimicrobial stewardship, only $28.6 \%$ of them replied that AMS is effective in improving patient outcomes, and about $25 \%$ of them responded that AMS is effective

Table 2 Knowledge, attitude, and practice of nurses regarding antimicrobial stewardship before and after educational program

\begin{tabular}{|c|c|c|c|c|}
\hline & Pre-education & Post-education & Wilcoxon test & $P$ value \\
\hline \multicolumn{5}{|l|}{ Knowledge } \\
\hline Mean \pm SD & $13.3 \pm 2.6$ & $18.0 \pm 1.02$ & 3.9 & $0.001^{*}$ \\
\hline Range & $8.0-17.0$ & $16.0-20.0$ & & \\
\hline \multicolumn{5}{|l|}{ Attitude } \\
\hline Mean \pm SD & $14.8 \pm 3.1$ & $15.7 \pm 0.51$ & 3.3 & $0.001^{*}$ \\
\hline Range & $7.0-16.0$ & $15-16.0$ & & \\
\hline \multicolumn{5}{|l|}{ Practice } \\
\hline Mean \pm SD & $9.3 \pm 2.3$ & $11.5 \pm 1.46$ & 2.8 & $0.004^{*}$ \\
\hline Range & $5.0-14.0$ & $8.0-14.0$ & & \\
\hline
\end{tabular}

*Significant in improving patient safety. About 32.1\% of them responded that AMS is effective in reducing resistance and in reducing healthcare cost (Fig. 3).

This education intervention about AMS among the respondents' physicians and pharmacists was effective in increasing the percent of positive attitude from $85.7 \%$ preintervention to $100 \%$ post-intervention $(P$ value $<0.05)$. (Table 1) and also was effective in improving attitude of the respondents' nurses with total score $14.8 / 16$ pre-intervention vs. $15.7 / 16$ post-intervention $(P<0.001)$ (Table 2$)$.

These educational workshops were found to be effective in improving the practice of the respondents' physicians (from $31.8 \%$ of them had good practice to $95.5 \%$ post-intervention) (Table 1) and also for nurses (from pre-education practice score $9.3 / 14$ to $11.5 / 14$ post-educational) (Table 2); however, there was non-significant improvement in practice of pharmacists (from absence of good practice pre-intervention to $33.3 \%$ post-intervention) $(P>0.05)$.

\section{Discussion}

This study was addressed to evaluate health care providers' knowledge, attitude, and practice about antimicrobial stewardship and antimicrobial resistance. To the best of our knowledge, this study was the first to assess these aspects among HCPs in Egypt. This study resulted in significant improvement in knowledge, attitude of the respondents' HCPs and practice of the respondents' physicians and nurses after the educational intervention $(P<$ $0.05)$, signifying that this educational program was effective and beneficial for AMS program. Many other studies suggested the positive effect of educational program on improvement of knowledge and practice [18-21]. 


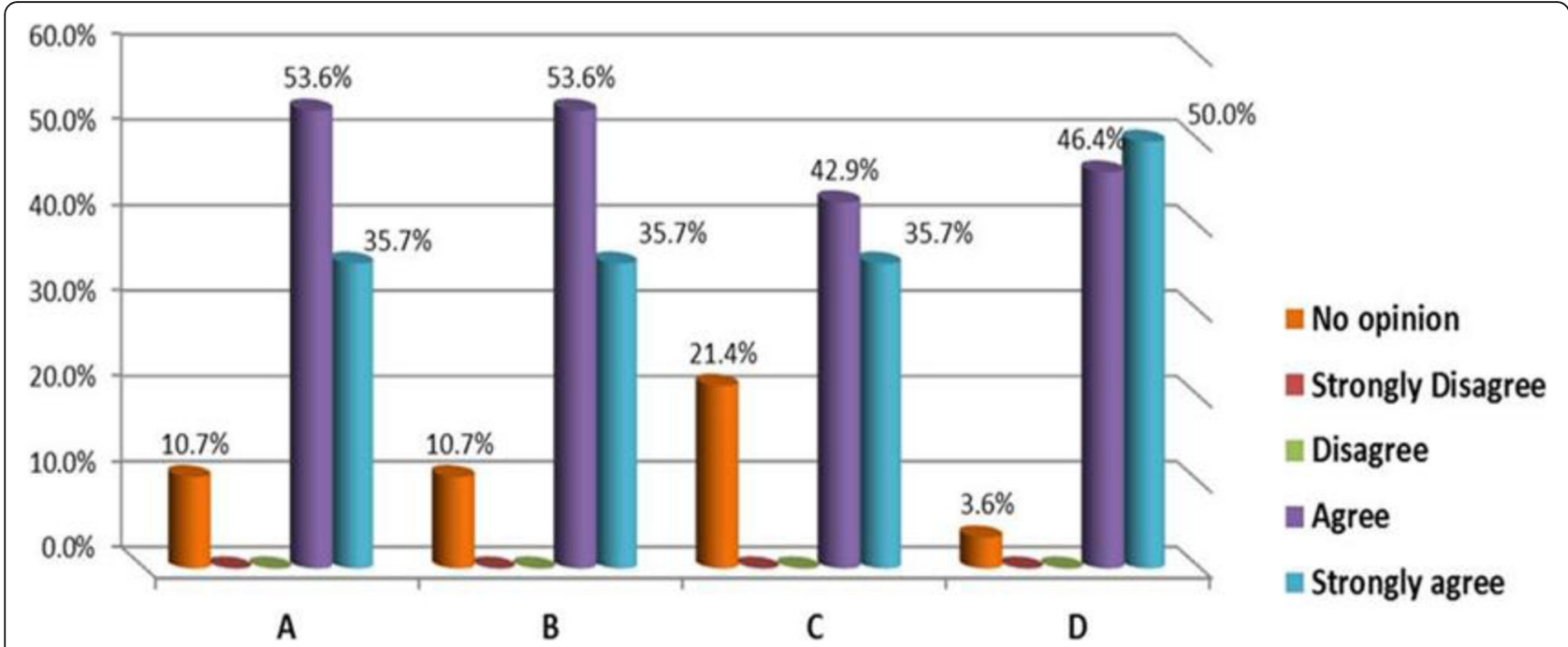

Fig. 1 Pre-education basic knowledge of the respondents' physicians and pharmacists about antimicrobial use. a. Inappropriate antibiotics use can lead to resistance, $\mathbf{b}$. Inappropriate antibiotics use can lead to ineffective treatment, $\mathbf{c}$. Inappropriate antibiotics use can lead to increase adverse effects, $\mathbf{d}$. Inappropriate antibiotics use gives additional burden of medical cost to the patient

Only 48 ones from the invited HCPs (69) participated in this educational workshop with attendance response rate of $70 \%$. We hoped to achieve a $95 \%$ response rate, but despite continued efforts over the 6-month study period to obtain a better response rate, we faced reluctance from the professors and assistant professors at the surgical department and ICU to attend the workshop; by this way, the response rate of physicians was $52 \%$, incomparable with pharmacists whose response rate was $100 \%$ and nurses whose response rate was above $85.0 \%$.

The familiarity of physicians and pharmacists with the term of AMS and antibiogram was poor preintervention. The same was observed by Tegagn et al. who reported that more than half of healthcare professionals were not familiar with the term antimicrobial stewardship and antibiogram [14]; however, it was less than that reported in another study conducted in South Africa that revealed most of the respondents were familiar with antimicrobial stewardship programs (71.9\%) and claimed to know what antimicrobial stewardship is (83.5\%) [22]. And also, lower than that was observed in a study conducted by Cotta and colleagues in which $80.0 \%$ of the pharmacists had heard about antimicrobial stewardship [23]. This poor level of knowledge could be due to the absence of education, basic training, and promotion of antimicrobial stewardship program across NLI. However, familiarity of physicians and pharmacists with antibiotic resistance (85\%) was appreciable which comes in line with Tegagn et al. who found that $81.3 \%$ of healthcare professionals were familiar with antibiotic resistance (81.3\%) [14].

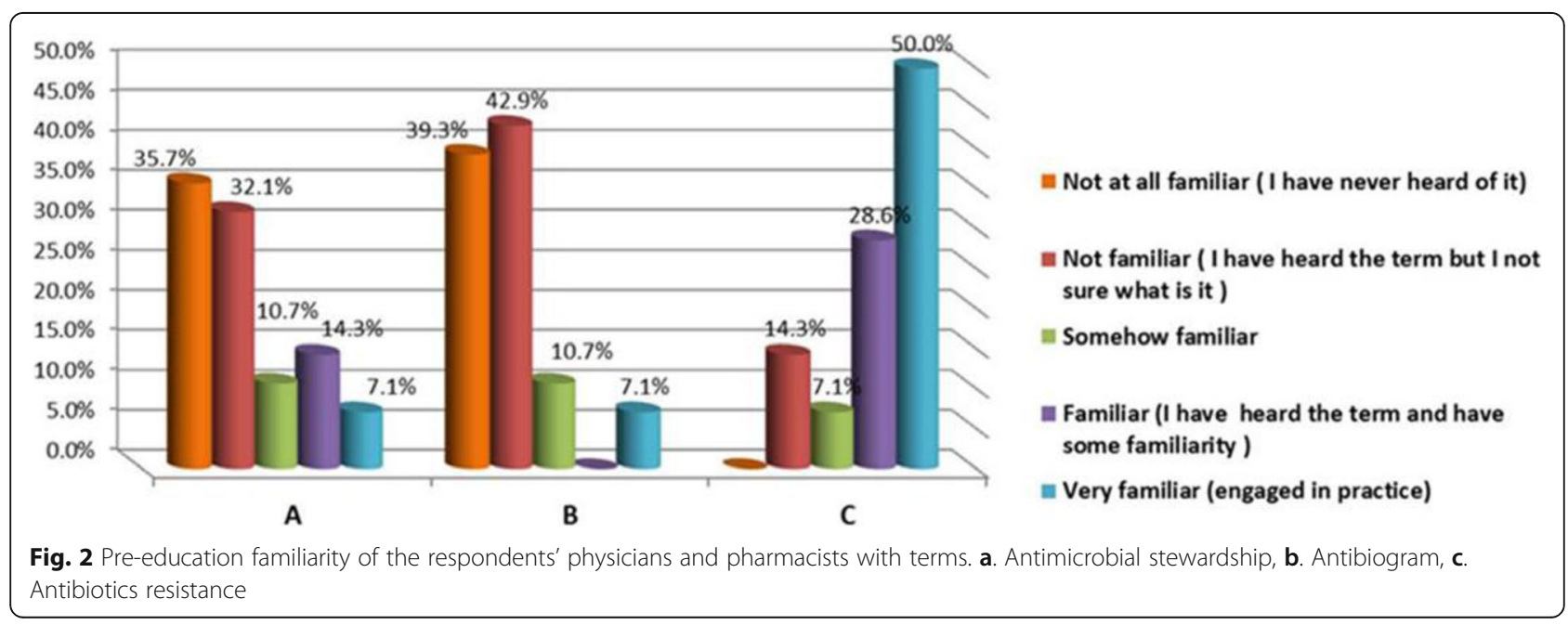




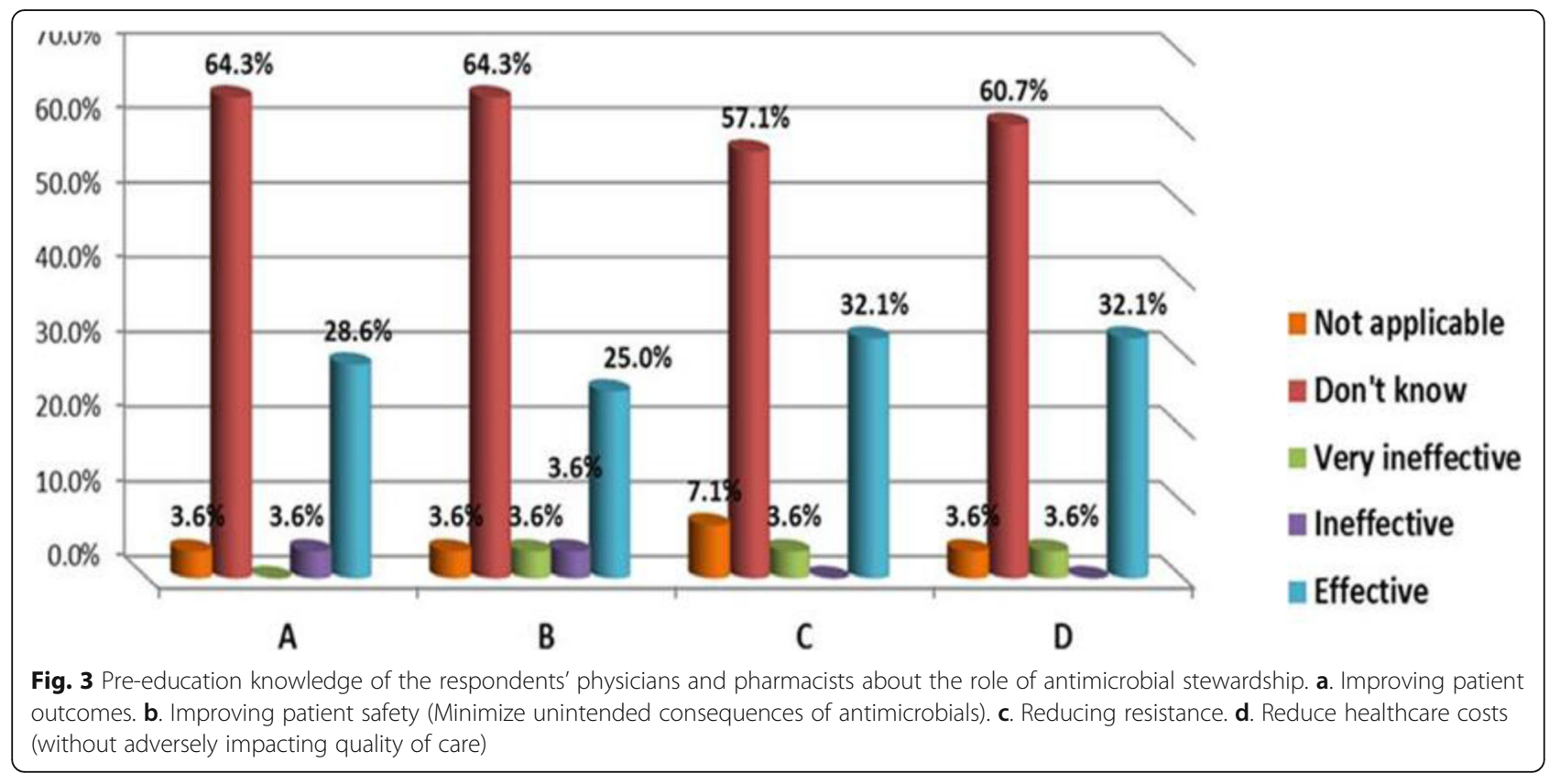

Before conduction of the educational program, the majority of respondents' physicians and pharmacists do not know the role of antimicrobial stewardship. This is related to their lack of knowledge regarding AMS term at first. This result is considered poor when compared to another study which revealed that about half of the respondents know antimicrobial stewardship effectiveness [22].

Before conduction of educational program, there was overall poor practice. This is explained by lack of knowledge about appropriate antimicrobials use and practices in the pre-education period. Lack of clinical education, skill expertise [24], and practice style traits [25] have all been documented as influencing a medical professional's use of evidence-based practice. Posteducation, there was significant statistical improvement in practices. This could be justified by improving knowledge post-intervention. This finding coincides with many studies which supported the positive correlation between knowledge and practices [26-30].

Finally, among the main limitations of this study was the use of a self-rated assessment tool, where healthcare providers might have overestimated their attitude level. Additionally, this study was conducted among healthcare providers in two departments. Hence, the result of this study could not be generalized to all other hospitals in Egypt.

\section{Conclusion}

The implemented educational program was successful in improving the knowledge, attitude, and practice of health care providers about AMS. Thus, continuous efforts for increasing the awareness and improving the attitude towards antimicrobial stewardship among healthcare providers should be prioritized by implementing different strategies, education modules, and the provision of appropriate training programs at regular intervals. We will record our lectures and publish them on Youtube channel and also design educational posters regarding AMS.

\section{Abbreviations}

AMS: Antimicrobial stewardship program; CDC: Center for disease prevention and control; KAP: Knowledge, attitude, and practice; HCPs: Health care providers; WHO: World Health Organization

\section{Acknowledgements}

We would like to give our grateful thanks to AMS Dr. Mona Mohammed Abd-Elhamied, clinical pharmacist at the NLI hospital, for their help in preparing the content of workshop and presenting session for antibiotic classes and uses.

\section{Authors' contributions}

MA collected, analyzed, and interpreted the study data and contributed to the manuscript writing. WM and SM contributed to the manuscript writing. $\mathrm{SE}, \mathrm{EH}$, and MK were major contributors to the manuscript writing and revising. All authors read and approved the final manuscript.

\section{Funding}

Not applicable

\section{Availability of data and materials}

The data that support the finding of this study are available from the corresponding author upon reasonable request

\section{Ethics approval and consent to participate}

The research ethics review committee of the National Liver Institute Menoufia University (IRB00003413) approved the study regarding confidentiality and the written consent with approval number 000178. The researcher introduced herself to the participants in the sample and explained the objectives of the study, to obtain their acceptance to be recruited in the study as well as to gain their cooperation by applying the consent form before the questionnaire

Consent for publication

Not applicable. 


\section{Competing interests}

The authors declare that they have no competing interests.

\begin{abstract}
Author details
'Epidemiology and Preventive Medicine Department, National Liver Institute, Menoufia University, Gamal Abdel Nasser Street, Shebein El-Kom, Menoufia, Egypt. ${ }^{2}$ Anaethesia and Intensive Care, National Liver Institute, Menoufia University, Shebein El-Kom, Egypt. ${ }^{3}$ Hepato-Pancreato-Biliary Surgery Department, National liver Institute, Menoufia University, Shebein El-Kom, Egypt. ${ }^{4}$ Clinical microbiology and immunology and molecular microbiology in liver and GIT, Shebein El-Kom, Egypt.
\end{abstract}

Received: 12 September 2019 Accepted: 12 December 2019 Published online: 10 February 2020

\section{References}

1. Centers for Disease Control and Prevention (2013) Antibiotic resistance threats in the United States, 2013Atlanta, GA: CDC. Available:http://www. cdc.gov/drugresistance/threat-report-2013/pdf/ar-threats-2013-508.pdf.

2. The White House (2015) National Action Plan for Combating AntibioticResistant Bacteria. . available:https://www.whitehouse.gov/sites/default/files/ docs/national_action_plan_for_combating_antibotic-resistant_bacteria.pdf.

3. Lautenbach E, Weiner MG, Nachamkin I, Bilker WB, Sheridan A, Fishman NO (2006) Imipenem resistance among Pseudomonas aeruginosa isolates: risk factors for infection and impact of resistance on clinicaland economic outcomes. Infect Control Hospital Epidemiol 27 (9):893-900. PMID:16941312

4. Srinivasan A (2017) Antibiotic stewardship: why we must, how we can. Cleveland Clin J Med 84(9):673-679. https://doi.org/10.3949/ccjm.84gr.17003

5. Merrill K, Hanson SF, Sumner S, Vento T, Veillette J, Webb B (2019) Antimicrobial stewardship: staff nurse knowledge and attitudes. Am J Infect Control 22:234-239. https://doi.org/10.1016/j.ajic.2019.03.022]

6. Ruiz J, Ramirez P, Gordon M, Villarreal E, Frasquet J, Poveda-Andres J, Catellanos A (2018) Antimicrobial stewardship programme in critical care medicine: a prospective interventional study. Med Intensiva 42(5):266-273. https://doi.org/10.1016/j.medin.2017.07.002

7. Sick AC, Lehmann CU, Tamma PD, Lee CK, Agwu AL (2013) Sustained savings from a longitudinal cost analysis of an internet-based preapproval antimicrobial stewardship program. journal of the. Soc Hospital Epidemiol Am 4(6):573-580

8. Pulcini C, Gyssens IC (2013) How to educate prescribers in antimicrobial stewardship practices. Virulence 4(2):192-202. https://doi.org/10.4161/viru.23706

9. Dellit TH, Owens RC, McGowan JE, Gerding DN, Weinstein RA, Burke JP, Huskins WC, Paterson DL, Fishman NO, Carpenter CF, Brennan PJ, Billeter M, Hooton TM (2007) Infectious Diseases Society of America and the Society for Healthcare Epidemiology of America Guidelines for developing an institutional program to enhance antimicrobial stewardship. Clin Infect Dis. 44:159-177. https://doi.org/10.1086/510393

10. Costelloe C, Metcalfe C, Lovering A, Mant D, Hay AD (2010) Effect of antibiotic prescribing in primary care on antimicrobial resistance in individual patients: systematic review and meta-analysis. BMJ. 340:2096. https://doi.org/10.1136/bmj.c2096

11. Davey P, Brown E, Charani E, Fenelon L, Gould IM, Holmes A, Ramsay CR, Wiffen PJ, Wilcox M (2013) Interventions to improve antibiotic prescribing practices for hospital inpatients. Cochrane Database Syst Rev:35-43. https://doi.org/10.1002/14651858.CD003543

12. Cooper BS, Stone SP, Kibbler CC, Cookson BD, Roberts JA, Medley GF, Duckworth GJ, Lai R, Ebrahim S (2003) Systematic review of isolation policies in the hospital management of methicillin-resistant Staphylococcus aureus: a review of the literature with epidemiological and economic modelling. Health Technol Assess 7:1-194

13. Davey P, Brown E, Fenelon L, Finch R, Gould I, Holmes A, Ramsay C, Taylor E, Wiffen P, Wilcox M (2006) Systematic review of antimicrobial drug prescribing in hospitals. Emerging Infect Dis 12:211-216. https://doi.org/10. 3201/eid1202.050145

14. Tegagn GT, Yadesa TM, Ahmed Y (2017) Knowledge, attitudes and practices of healthcare professionals towards antimicrobial stewardship and their predictors in Fitche Hospital. J Bioanalysis Biomed 9(2):91-97. https://doi. org/10.4172/1948-593x.1000159

15. Sarwar M, Saqib A, Iftikhar S, Sadiq T (2018) Knowledge of community pharmacists about antibiotics, and their perceptions and practices regarding antimicrobial stewardship: a cross-sectional study in Punjab, Pakistan. Infect Drug Resistance 11:133-145. https://doi.org/10.2147/idr.s148102

16. McEwen J, Burnett E (2018) Antimicrobial stewardship and pre-registration student nurses: evaluation of teaching. J Infect Prevention 19(2):80-86. https://doi.org/10.1177/1757177417726156

17. WHO (2019) https://openwho.org/courses/AMR-competency

18. Eze CN, Ebuehi OM, Brigo F, Otte WM, Igwe SC (2015) Effect of health education on trainee teachers' knowledge, attitudes, and first aid management of epilepsy: an interventional study. Seizure. 33:46-53. https://doi.org/10.1016/j.seizure

19. Cooper C, Huzzey L, Livingston G (2012) The effect of an educational intervention on junior doctors' knowledge and practice in detecting and managing elder abuse. Int Psychogeriatr. 24(9):1447-1453. https://doi.org/ 10.1017/S1041610212000403 Epub 2012 Mar 30

20. MC MN, Harmon D, Saunders J (2012) Effect of education on knowledge, skills and attitudes around pain. Br J Nurs 21(16):958, 960-958, 964

21. Lin PC, Chiang HW, Chiang TT, Chen CS (2008) Pain management: evaluating the effectiveness of an educational programme for surgical nursing staff. J Clin Nurs 17(15):2032-2041

22. Burger M, Fourie J, Loots D, Mnisi T, Schellack N, Bezuidenhout S, Meyer JC (2016) Knowledge and perceptions of antimicrobial stewardship concepts among final year pharmacy students in pharmacy schools across South Africa. Southern Afr J Infect Dis 31(3):84-90. https://doi.org/10.1080/ 23120053.2016.1192808

23. Cotta MO, Robertson MS, Tacey M et al (2016) Attitudes towards antimicrobial stewardship: results from a large private hospital in Australia. Healthcare Infect 19(3):89-94 Available from: https://doi.org/10.1071/HI14008

24. Cochrane LJ, Olson CA, Murray S, Dupis M, Tooman T, Hayes S (2007) Gaps between knowing and doing: understanding and assessing the barriers to optimal health care. J Contin Educ Health Prof. 27(2):94-102

25. Korner-Bitensky N, Menon-Nair A, Thomas A, Boutin E, Arafah AM (2007) Practice style traits: do they help explain practice behaviors of stroke rehabilitation professionals? J Rehabil Med. 39:685-692

26. Dowell $L J$ (1969) The relationship between knowledge and practice. J Educ Res 62(5):201-205. https://doi.org/10.1080/00220671.1969.10883815

27. Yahya KM, Yusoff RM (2012) Association between knowledge, attitude and practice on cardiovascular disease among women. Int J Collaborative Res Inter Med Public Health 4(8)

28. Yap J, Lee VJ, Yau TY, Phern-Chern T (2010) Knowledge, attitudes and practices towards pandemic influenza among cases, close contacts, and healthcare workers in tropical Singapore: a cross-sectional survey. BMC Public Health 10:442

29. Abebe DS, Biffa D, Bjune G, Ameni G, Abebe F (2011) Assessment of knowledge and practice about tuberculosis among eastern Ethiopian prisoners. Int J Tuberc Lung Dis 15(2):228-233

30. Launiala A, Honkasalo ML (2007) Ethnographic study of factors influencing compliance to intermittent preventive treatment of malaria during pregnancy among Yao women in rural Malawi. Trans R Soc Trop Med Hyg 101(10):980-989

\section{Publisher's Note}

Springer Nature remains neutral with regard to jurisdictional claims in published maps and institutional affiliations.

\section{Submit your manuscript to a SpringerOpen ${ }^{\circ}$ journal and benefit from:}

- Convenient online submission

- Rigorous peer review

- Open access: articles freely available online

High visibility within the field

- Retaining the copyright to your article

Submit your next manuscript at $>$ springeropen.com 